\title{
Lignin/Si Hybrid Carbon Nanofibers towards Highly Efficient Sustainable Li-ion Anode Materials
}

\author{
Mario Culebras, ${ }^{1,4}$ Gearoid A. Collins, ${ }^{2}$ Anne Beaucamp, ${ }^{1}$ Hugh Geaney ${ }^{2}$ and Maurice N. Collins $1,3^{*}$
}

\begin{abstract}
As fossil fuel resources dwindle and new regulations for a cleaner and safer environment come onstream, there is a growing interest in developing new sustainable feedstocks for future applications. Lignocellulosic biomass is the feedstock of choice but remains underutilized and is mostly considered waste. Therefore, the present study shows the preparation of ligninderived carbon nanofibre (CNFs)/Si hybrid nanostructures to be used as high-performance anodes for Li-ion batteries. Scanning electron microscopy (SEM) shows the evolution of the morphology after each processing step (electrospinning, stabilization, and carbonization) and as a function of the Si content. The electrochemical analysis of the electrodes produced shows promising capacity values. The addition of Si elevated the achievable specific capacity of CNF, with 5,10 , and $15 \%$ of Si reaching respective capacity values of $274,439,602$, and $921 \mathrm{mAh} \mathrm{g}^{-1}$. Thus, these results show the enormous potential of lignocellulose waste materials as high-performance energy storage materials.
\end{abstract}

Keywords: Lignin; Energy storage; Carbon nanofibers.

Received: 07 November 2021; Revised: 04 January 2022; Accepted: 06 January 2022.

Article type: Research article.

\section{Introduction}

Energy storage devices have become one of the most important technological areas in the context of the sustainable development of modern society. With the increasing demand for electric vehicles and energy-hungry multifunctional portable electronic devices such as smartphones, laptops, tablets, and biomedical sensing equipment, more efficient and cost-effective energy storage devices such as batteries and supercapacitors are required to meet these demands. ${ }^{[1-4]}$ The circular use of raw materials in the manufacture of energy storage devices is a crucial component to achieve the sustainable goals proposed by the United Nations and promoted via initiatives such as the European Union Green Deal, which has an overall objective of making Europe climate neutral by 2050. While lithium-ion batteries (LIBs) are considered one of the most efficient energy storage devices and therefore their use in electronic devices and electric

\footnotetext{
${ }^{1}$ Stokes Laboratories \& School of Engineering, Bernal Institute,

University of Limerick, Ireland.

${ }^{2}$ Bernal Institute \& Chemical Sciences Department, University of

Limerick, Ireland.

${ }^{3}$ Advanced Materials and Bioengineering Research (AMBER)

Centre, Ireland.

${ }^{4}$ Institute of Material Science of the University of Valencia, Spain.

*Email: Maurice.collins@ul.ie (M. Collins)
}

vehicles has increased dramatically. ${ }^{[5-7]}$ Graphite is the standard anode material for commercial LIBs, however, it poses several problems, for example, its low theoretical capacity of just $372 \mathrm{mAhg}^{-1}$. In addition, graphite, which is produced mainly by mining activities, is associated with several environmental problems, such as groundwater contamination, soil contamination, air pollution, health hazards, and mining waste. ${ }^{[8]}$ Therefore, a large number of investigations are currently focused on the development of new technologies capable of producing graphite and carbonbased materials from sustainable precursors that can contribute to the circular use of products and reduce the environmental impact of the battery industry. ${ }^{[9]}$

Lignin is the most abundant aromatic biopolymer on the planet. It is amorphous and is present in the cell wall of plants. Currently, it is a non-valorized waste from the paper and pulp industry with only $2 \%$ of the total lignin production commercialized. The aromatic molecular structure of lignin generated by the condensation of three different monolignols (coniferyl alcohol, sinapyl alcohol, and p-coumaryl alcohol) renders it ideal for carbon production. ${ }^{[10]}$ Lignin-based carbon nanostructures and in particular carbon nanofibers (CNFs) have been explored as sustainable alternatives to traditional graphite. ${ }^{[1-15]}$ Typically, lignin is combined with other polymers (polyacrylonitrile and polyethylene glycol) to allow its processability during the electrospinning process due to its 
low viscosity. ${ }^{[16,17]}$ These lignin blends have shown capacity values that are competitive to graphite (300-500 $\left.\mathrm{mAh} \mathrm{g}^{-1}\right),{ }^{[11-}$ 15] while offering the possibility of further performance enhancement via nitrogen doping. ${ }^{[18]}$ Additionally, fully sustainable lignin/poly(lactic acid) (PLA) blends were recently studied by the current authors, to produce CNFs where the addition of PLA generates a mesoporous structure within the nanofibres due to its volatile nature and the phase separation processes between lignin and PLA. These fully biobased fibers display excellent capacity values and stability achieving $611 \mathrm{mAhg}^{-1}$ after 500 cycles. ${ }^{[11]}$

Here, we examine the use of these sustainable CNFs derived from lignin/PLA as an electrochemically active support for $\mathrm{Si}$ nanostructures. The addition of inorganic nanostructures with a high theoretical capacity such as $\mathrm{Si}$ (3579 $\left.\mathrm{mAh} \mathrm{g}^{-1}\right), \mathrm{ZnO}\left(978 \mathrm{mAh} \mathrm{g}^{-1}\right)$, or $\mathrm{GeO}_{2}\left(2152 \mathrm{mAh} \mathrm{g}^{-1}\right)$, has been previously utilized to provide a remarkable improvement in the gravimetric capacity of petroleum-derived CNFs. ${ }^{[19-22]}$ However, in this work, we have developed a new and unique mesoporous hybrid $\mathrm{Si} / \mathrm{CNF}$ s derived from fully sustainable precursors which reach a capacity of $921 \mathrm{mAh} \mathrm{g}^{-1}$ with only $15 \% \mathrm{Si}$ loading. This represents not only a massive opportunity for lignin valorization in the battery industry but also highlights the potential of sustainable materials as advanced materials with performance levels higher than their fossil equivalents, therefore reaching beyond the current state of the art whilst offering enormous commercial opportunities.

\section{Experimental}

\subsection{Materials}

Alcell Organosolv hardwood lignin was obtained from Tecnaro GmbH. (Germany). PLA (Ingeo Biopolymer 3001D) injection molding grade was purchased from Natureworks, Minnetonka. Dimethylformamide (DMF), tetrahydrofuran (THF) and methylene diphenyl diisocyanate (MDI), and $\mathrm{Si}$ nanopowder $(100 \mathrm{~nm})$ were purchased from Sigma Aldrich (Germany). $\mathrm{Cu}$ foil ( $9 \mu \mathrm{m}$ thick) was purchased from Pi-Kem. Carboxymethyl cellulose (CMC, $\geq 1900 \mathrm{mPa}$ s) and Super P conductive carbon black (CB) were purchased from VWR and MTI Corporation, respectively. The $1.0 \mathrm{M} \mathrm{LiPF}_{6}$ in EC-DEC $(1: 1 \mathrm{v} / \mathrm{v})$ electrolyte and vinylene carbonate (VC, 97\%) additive were purchased from Sigma Aldrich.

\subsection{Solution preparation}

All solutions were prepared using the same method but with different concentrations of $\mathrm{Si}$ as seen in Table 1. PLA was first dissolved in a mixture of THF: DMF for $1 \mathrm{~h}$ under magnetic stirring at $60{ }^{\circ} \mathrm{C}$ and $1300 \mathrm{rpm}$. Once PLA was dissolved, lignin was added to the solution to be mixed for $30 \mathrm{~min}$. Once lignin was dissolved, $\mathrm{Si}$ was added to the solution and mixed for $10 \mathrm{~min}$ before sonicating for $20 \mathrm{~min}$. Finally, the crosslinker (MDI) was dissolved in the solution for $5 \mathrm{~min}$ and was ready to be electrospun. The sample without $\mathrm{Si}$ did not require sonication and could be electrospun $5 \mathrm{~min}$ after the crosslinker was dissolved.
Table 1. Sample composition of the electrospinning solutions.

\begin{tabular}{|c|c|c|c|c|c|}
\hline Sample & $\mathrm{Si}$ (g) & Lignin (g) & $\operatorname{PLA}(\mathrm{g})$ & $\begin{array}{l}\text { MDI } \\
(\mathrm{mg})\end{array}$ & THF (mL) \\
\hline $\begin{array}{l}\text { CNF/Si } 0 \\
(0 \% \mathrm{Si})\end{array}$ & 0 & 1.86 & 2 & 0.14 & 8.99 \\
\hline $\begin{array}{l}\mathrm{CNF} / \mathrm{Si} 5 \\
(5 \% \mathrm{Si})\end{array}$ & 0.21 & 1.86 & 2 & 0.14 & 8.99 \\
\hline $\begin{array}{l}\mathrm{CNF} / \mathrm{Si} \\
10(10 \% \\
\mathrm{Si})\end{array}$ & 0.44 & 1.86 & 2 & 0.14 & 8.99 \\
\hline $\begin{array}{l}\mathrm{CNF} / \mathrm{Si} \\
15 \quad(15 \% \\
\mathrm{Si})\end{array}$ & 0.7 & 1.86 & 2 & 0.14 & 8.99 \\
\hline
\end{tabular}

\subsection{Preparation of precursor CNFs}

An electrospinning setup composed of a syringe driver (Harvard PHD 2000)) and a power source (SIMCO Euro charger Master) was used to produce nanofibers. The solution was loaded into a syringe and placed on the syringe driver. The electrospinning parameters were established as follows. The infusion rate was set at $30 \mu \mathrm{L} / \mathrm{min}$; the applied voltage at 7.7 $\mathrm{kV}$, and the distance between the collector plate and the needle at $10 \mathrm{~cm}$. For the solutions with $\mathrm{Si}, 10.6 \mathrm{kV}$ was used because it was found to be the optimum voltage for electrospinning. A copper sheet was used as a collector plate. After one hour of electrospinning, the collector was removed, and it was ready for stabilization.

\subsection{Carbonisation of precursor nanofibers}

Prior to the carbonization step, the precursor nanofibers were thermo-stabilized using the following temperature program. Initially, the temperature was ramped from 25 to $150{ }^{\circ} \mathrm{C}$ at $1{ }^{\circ} \mathrm{C} \mathrm{min}{ }^{-1}$ and kept at $150{ }^{\circ} \mathrm{C}$ for $14 \mathrm{~h}$. Then the temperature was raised from 150 to $200^{\circ} \mathrm{C}$ at $1{ }^{\circ} \mathrm{C} \mathrm{min}-1$ and kept at $200{ }^{\circ} \mathrm{C}$ for $1 \mathrm{~h}$ and then the temperature was ramped again from 200 to $250{ }^{\circ} \mathrm{C}$ at $1{ }^{\circ} \mathrm{C} \min ^{-1}$ and kept at $250{ }^{\circ} \mathrm{C}$ for $1 \mathrm{~h}$. The stabilized nanofibers were finally carbonized using a tubular furnace heating from room temperature to $900{ }^{\circ} \mathrm{C}$ at $10^{\circ} \mathrm{C}$ $\min ^{-1}$ under nitrogen flow and kept at $900^{\circ} \mathrm{C}$ for 30 minutes. After the carbonization steps, the CNFs were removed from the copper sheets using a metallic spatula.

\subsection{Electrode preparation \& electrochemical analysis}

Anodes of the four different CNF/Si compositions (0, 5, 10, and $15 \mathrm{wt} \% \mathrm{Si}$ ) were fabricated via a typical slurry processing technique. A slurry composition of $80 \mathrm{wt} \%$ active material, 10 $\mathrm{wt} \%$ carbon black (CB), and $10 \mathrm{wt} \%$ carboxymethyl cellulose (CMC) was used for each configuration. Firstly, CB was homogeneously dispersed in a binder solution of $1.5 \mathrm{wt} \%$ $\mathrm{CMC}$ in $\mathrm{H}_{2} \mathrm{O}$. The mixture was left to stir for $6 \mathrm{~h}$ to ensure uniform dispersion of $\mathrm{CB}$, behaving as a conductive network for the active material. Afterward, the $\mathrm{CNF} / \mathrm{Si}$ (or $\mathrm{CNF}$ ) composite powder was added slowly and incrementally with constant stirring to prevent clumping. The slurry was left to stir overnight prior to casting. Using a heated vacuum doctor 
blade at $60{ }^{\circ} \mathrm{C}$, slurry tapes were cast on $\mathrm{Cu}$ foil $(9 \mu \mathrm{m}$, purchased from Pi-Kem). As the slurry was cast, the doctor bade height was varied from 20 to $40 \mu \mathrm{m}$, giving a good distribution of anode loadings. Anodes tapes were desiccated in a vacuum oven for $12 \mathrm{~h}$ at $120^{\circ} \mathrm{C}$ to remove residual water. Circular anodes $\left(0.64 \mathrm{~cm}^{2}\right)$ were punched out and stored under argon prior to cell assembly.

For electrochemical analysis, anode loadings for CNF and different $\mathrm{CNF} / \mathrm{Si}$ compositions were matched, with an average loading of $1.04 \pm 0.11 \mathrm{mg} \mathrm{cm}^{-2}$. CNF and CNF/Si anodes were tested in Li metal half-cells (HCs) using a BioLogic MPG-2 multichannel potentiostat. At first, electrochemical performance was analyzed over a preliminary potential range of $0.01-3.0 \mathrm{~V} \mathrm{vs} \mathrm{Li} / \mathrm{Li}^{+}$, and then over a narrower range of 0.01-1.0 V vs $\mathrm{Li} / \mathrm{Li}^{+}$. Anodes were tested in two-electrode Swagelok-type cells using a Celgard separator and a $1 \mathrm{M}$ $\mathrm{LiPF}_{6}$ in EC-DEC $(1: 1 \mathrm{v} / \mathrm{v})+3 \mathrm{wt} \%$ vinylene carbonate $(\mathrm{VC})$ electrolyte. To determine the specific capacities of CNF and different $\mathrm{CNF} / \mathrm{Si}$ compositions, a constant current density of $100 \mathrm{~mA} \mathrm{~g}^{-1}$ was used throughout testing. Quoted specific capacities are based on the total active mass of both CNF and $\mathrm{Si}$ components. Cyclic voltammetric $(\mathrm{CVs})$ were taken at a scan rate of $0.05 \mathrm{mV} \mathrm{s}^{-1}$ between potential limits of $0.01-3.0 \mathrm{~V}$ vs $\mathrm{Li} / \mathrm{Li}^{+}$and 0.01-1.0 $\mathrm{V}$ vs $\mathrm{Li} / \mathrm{Li}^{+}$.

\subsection{Characterization}

Scanning electron microscopy (SEM) was performed to determine the nanofiber morphology utilizing a Hitachi SU70 microscope at an accelerating voltage of $5 \mathrm{kV}$ and a working distance of $14 \mathrm{~mm}$. The electrodes were placed in a sample holder (ca $2 \mathrm{~cm}$ diameter) to study the sample surface. Energy dispersive X-ray spectroscopy (EDX) was performed using Oxford instruments X-Max EDS system coupled to the field emission scanning electron microscopy (FE-SEM) machine for elemental analysis. The electrodes were placed in a sample holder (2 cm diameter) to study the sample surface, accelerating voltage was at $5 \mathrm{kV}$ and at a working distance of $14 \mathrm{~mm}$. The Raman spectra of the CNFs were recorded at room temperature in a backscattering configuration with a Raman spectrometer (Horiba, LabRAM 1A) equipped with a $514 \mathrm{~nm}$ laser. The laser was focused to a spot size of $\sim 10 \mu \mathrm{m}$ onto the CNF surface using a $50 \times$ microscope objective (Olympus). To avoid sample damage, the laser power was limited to a few microwatts. All measurements were calibrated with the spectra of a silicon sample and the spectrometer was kept in the same position to avoid inaccuracy. X-ray diffraction (XRD) analysis was performed using a PANalytical $X$ 'Pert diffractometer. The machine was operated at $40 \mathrm{mV} / 40$ $\mathrm{mA}$, using a copper $(\mathrm{Cu})$ anode, at a step size of $0.008^{\circ}$ from $10^{\circ}$ to $100^{\circ}$. XRD was used to observe the phonon of $\mathrm{Si}$ in the $\mathrm{CNF} / \mathrm{Si}$ composite. X-ray photoelectron spectroscopy (XPS) was performed using a Kratos AXIS ULTRA spectrometer. This was used to analyze the surface of the sample and the surface elemental composition of the sample. Samples were measured at a sample temperature of $20-30{ }^{\circ} \mathrm{C}$. The X-ray gun used was mono Al $K_{\alpha} 1486.58 \mathrm{eV} ; 300 \mathrm{~W}(20 \mathrm{~mA}, 15 \mathrm{kV})$. The pass energy used was $16 \mathrm{eV}$ for the survey spectra and 20 $\mathrm{eV}$ for the narrow regions. For the electrochemical characterization, the samples were tested within two electrode Swagelok-type cells as the working electrode $v s$ a Li metal counter/reference electrode. All potentials are quoted relative to $\mathrm{Li} / \mathrm{Li}^{+}$. Celgard separators impregnated with a carbonatebased electrolyte (1.0 M lithium hexafluorophosphate ( $\left.\mathrm{LiPF}_{6}\right)$ solution in ethylene carbonate and diethyl carbonate, battery grade Aldrich) with $3 \mathrm{wt} \%$ vinylene carbonate (97\% Aldrich) were used. CNF and CNF/Si composite anodes were tested in half-cells $v s$ Li metal between potential limits of 0.01-3.0 V vs $\mathrm{Li} / \mathrm{Li}^{+}$and $0.01-1.0 \mathrm{~V}$ vs $\mathrm{Li} / \mathrm{Li}^{+}$, at a constant current density of $100 \mathrm{~mA} \mathrm{~g}^{-1}$. The potential window was selected to allow comparison with previous carbon nanofiber tests within the literature that use this range. ${ }^{[23-26]}$ Testing was conducted using a Biologic MPG-2. The cells were assembled and tested within an Ar-filled glovebox with $\mathrm{O}_{2}$ and $\mathrm{H}_{2} \mathrm{O}$ levels below $0.1 \mathrm{ppm}$.

\section{Results and discussion}

The electrospinning process of Lignin/Si solutions was carried out successfully with up to $15 \%$ of Si nanoparticles (NPs). It was observed during processing via electrospinning that higher concentrations of Si NPs resulted in discontinuities, generating heterogeneous dispositions on the current collector. Therefore, this study focuses on CNFs/Si with a silicon content between 0 and $15 \%$.

Figure 1(a) shows the resulting morphology of the CNFs/Si samples after each processing step, as produced, stabilized, and after carbonization. The nanofibers retained their fiber morphology after thermal stabilization and carbonization, indicating that the chemical crosslinking promoted by the generation of urethane bonds due to the reaction between MDI and the hydroxyl groups of lignin, is effective. ${ }^{[11]}$ The Si NPs were homogeneously distributed in the CNFs typically grouped in small clusters as can be observed in more detail in the SEM images Fig. 1(b) and EDS results shown in Fig. S1. Moreover, the Si nanoparticles are located within the pores generated after the carbonization step as illustrated in the schematic of Fig. 1(c). Previous studies of the lignin/PLAbased CNFs prove that they exhibit hierarchical porosity. The sacrificial nature of PLA creates voids up to $100 \mathrm{~nm}$ in diameter during carbonization and this also produces some lignin-induced mesopores of $2 \mathrm{~nm}$ radius. The resulting surface area of the material was measured at $670 \mathrm{~m}^{2} \cdot \mathrm{g}^{-1}$ with the aforementioned hierarchical nanostructure proving ideal for the nesting of Si NPs. ${ }^{[11,27]}$

Figure 2 shows double peaks centered at 1354 and 1596 $\mathrm{cm}^{-1}$, respectively $\mathrm{D}$ and $\mathrm{G}$ bands. The $\mathrm{D}$ band is representative of the boundaries of nanocrystallites of graphitic carbon and the $\mathrm{G}$ band refers to the $\mathrm{sp}^{2}$ vibrations of the ordered graphic crystallites. The ratio $\mathrm{R}=\mathrm{I}_{\mathrm{D}} / \mathrm{I}_{\mathrm{G}}$ is commonly used to quantify disorder within the carbonaceous structures, with low values corresponding to higher graphitic structures. ${ }^{[28,29]}$ The addition of silicon to the CNFs is confirmed by the apparition of two 

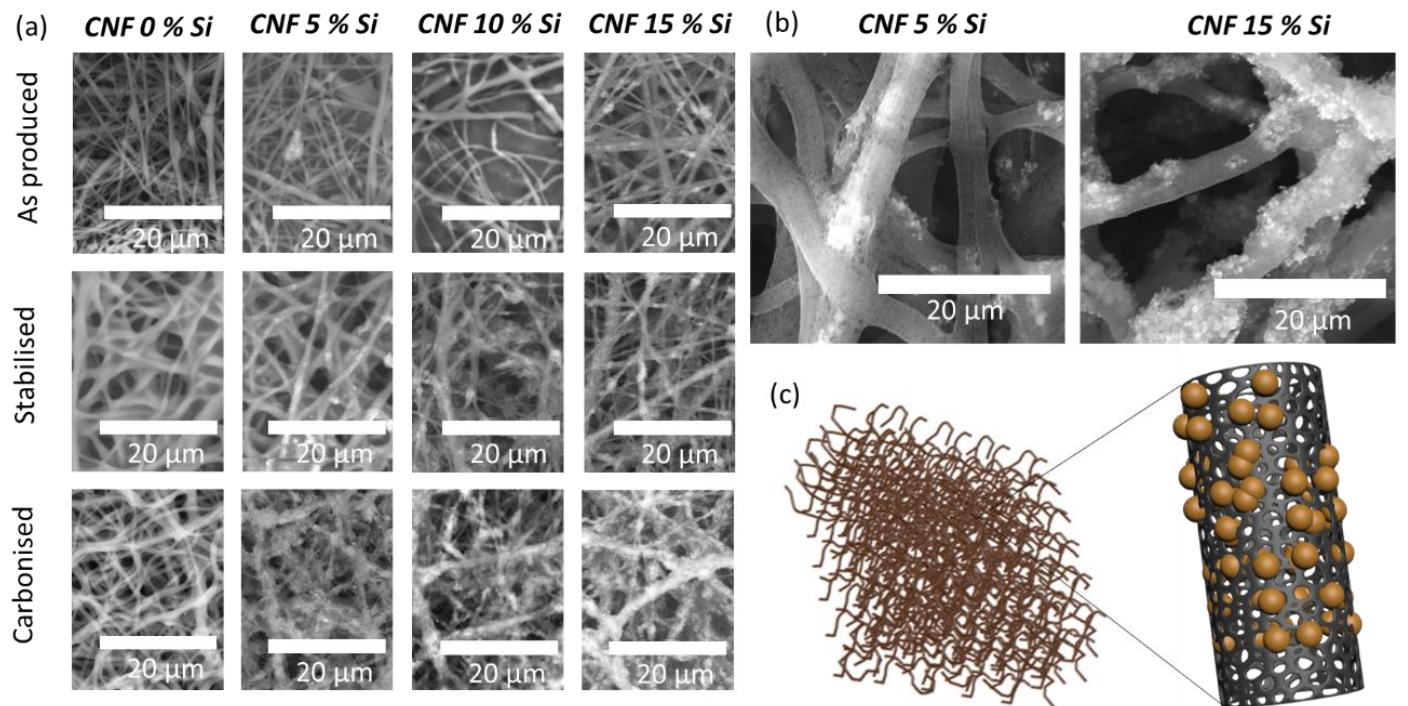

Fig. 1 SEM images of (a) CNF-Si at different production stages and (b) high magnification images of Si. (c) schematic of CNF/Si fibers.

Raman bands at 500 and $920 \mathrm{~cm}^{-1}$, characteristic of the first and second-order scattering of the Si nanostructures grown in amorphous silicon. ${ }^{[30]}$ To calculate $\mathrm{R}$ for the $\mathrm{Si}$ samples, the carbon double peaks were deconvoluted after the removal of the baseline. The addition of $15 \%$ of silicon to the CNFs increases significantly $\mathrm{R}$, as the presence of nanostructured $\mathrm{Si}$ hinders the graphitization of the carbon and increases the disorder within the turbostratic phase.

To characterize the surface chemistry of the $\mathrm{CNF} / \mathrm{Si}$ samples, XPS analysis was carried out as depicted in Fig. 3. The atomic ratio of $\mathrm{Si}: \mathrm{C}: \mathrm{O}: \mathrm{N}$ at the surface was $0: 90.6: 7.8: 16$, 3.1:87.8:8.3:0.8, 3.1:88.3:7.6:1 and 3.4:87.3:8.1:1.2 for the samples prepared with $0,5,10$, and $15 \%$ of $\mathrm{Si}$ NPs, respectively. These results confirm the presence of $\mathrm{Si}$ at the surface. ${ }^{[31]}$ However, the amount of $\mathrm{Si}$ at the surface did not change as a function of the $\mathrm{Si}$ concentration in the electrospinning solution, indicating a possible saturation of $\mathrm{Si}$ NPs at the surface. In contrast, SEM results show a clear increase in Si NPs content as a function of Si concentration which suggests that a large fraction of Si NPs is embedded in the lignin-derived carbon nanofibers. The $\mathrm{Si} 2 \mathrm{p}$ spectrum consists of XPS peaks at 99.6 and $100.2 \mathrm{eV}$, and these

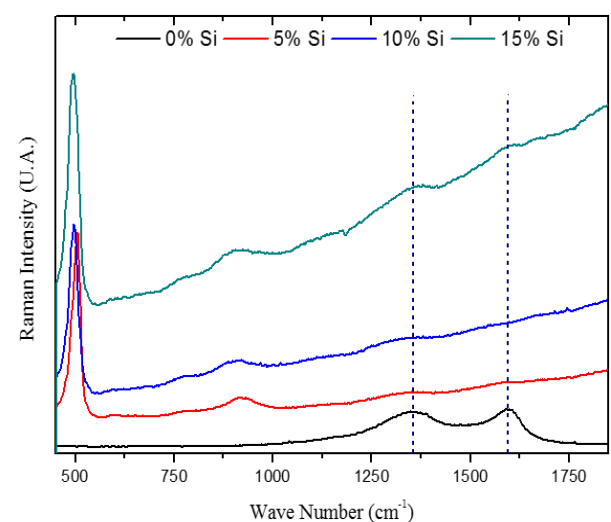

correspond to $\mathrm{Si}$ in its metallic state, the peak at $101.5 \mathrm{eV}$ is related to Si-N and the peaks at 104 and $104.6 \mathrm{eV}$ correspond to silicon oxide $(\mathrm{Si}(+4)$ and $\mathrm{Si}-\mathrm{O})$ indicating partial oxidation of the Si NPs at the surface of the nanofibres.

The C1s spectra for the CNFs/Si samples are plotted in the first column of Fig. 3. The peaks are mainly attributed to C-C at $284.1 \mathrm{eV}, \mathrm{C}=\mathrm{C}$ at $284.8 \mathrm{eV}, \mathrm{C}-\mathrm{N}$ at $285.4 \mathrm{eV}, \mathrm{C}-\mathrm{O}$ at 285.9 and $\mathrm{C}=\mathrm{O}$ at $287.7 \mathrm{eV}$. The signals for the $\mathrm{N} 1 \mathrm{~s}$ (second column in Fig. 3) spectra are very weak due to the low nitrogen content of the samples. The peaks at 398.5 and $401.1 \mathrm{eV}$ are attributed to N-Si and N-C. Finally, the O1s spectrum contained three peaks at 531.2, 533.1, and $534.6 \mathrm{eV}$, which are attributed to $\mathrm{O}=\mathrm{C}, \mathrm{O}-\mathrm{C}$, and $\mathrm{O}-\mathrm{Si}$, respectively.

From the XRD spectra in Fig. 4, it can be observed that all the peaks in the CNF/Si samples are well-matched with the peaks in pure $\mathrm{Si}$ nanoparticles. This indicates the clear presence of Si nanoparticles ( $\mathrm{Si}(0))$ within the samples. All the observed Si peaks appear at $28^{\circ}, 47^{\circ}, 56^{\circ}, 69^{\circ}, 76^{\circ}, 88^{\circ}$ and $94^{\circ}$ corresponding to (111), (220), (311), (400), (331), (422), and (511) diffraction planes of the diamond cubic crystals of $\mathrm{Si}$. The increase of $\mathrm{Si}$ content in the samples is reflected in the increase in the intensity of the Si peaks as it

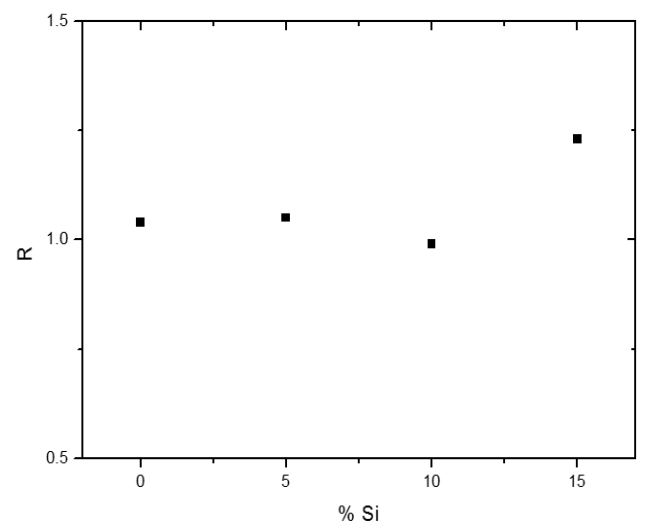

Fig. 2 Raman spectra for the CNFs at various Si content (a) and evolution of the ratio of the intensity of D and G bands for carbon. 

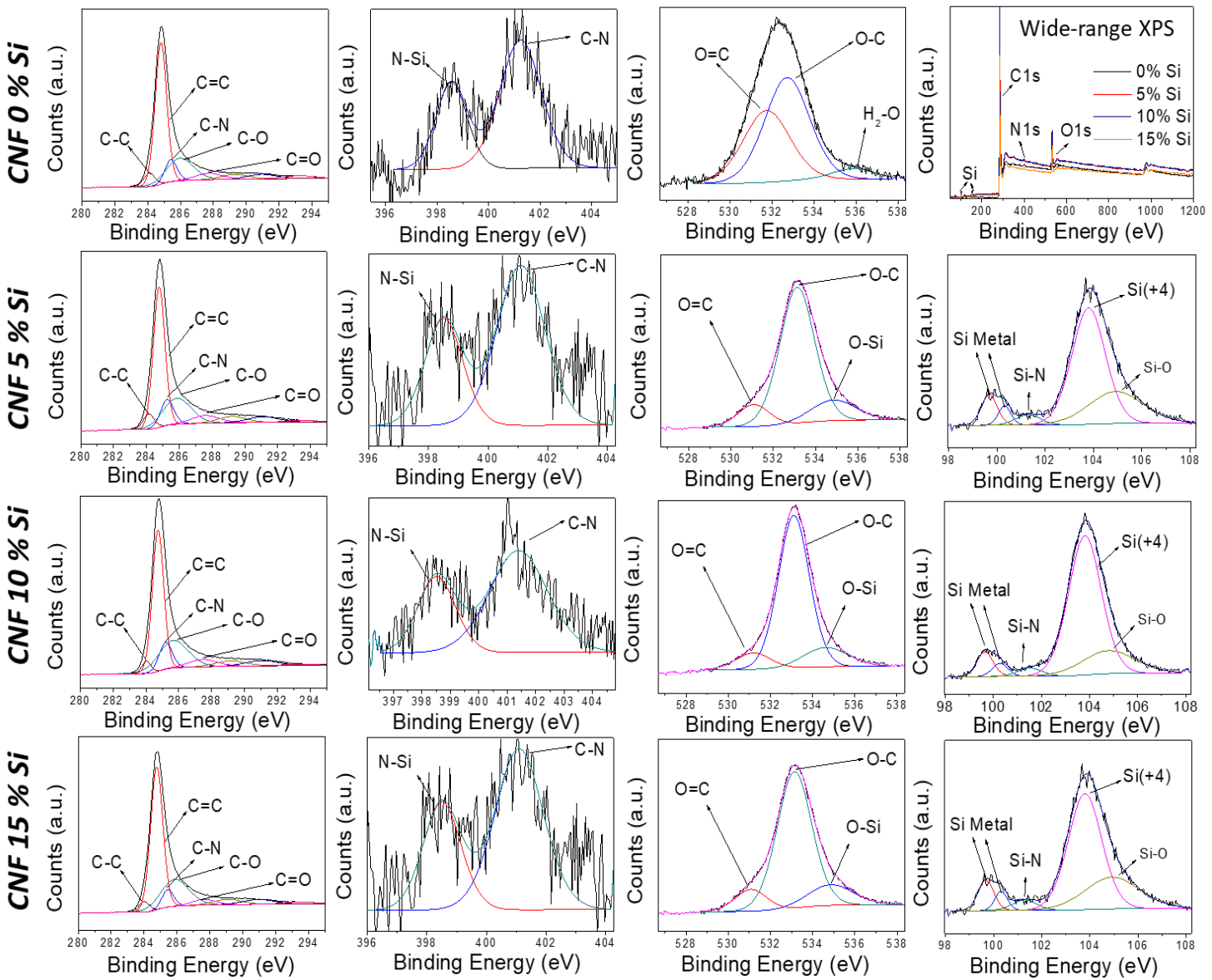

Fig. 3 XPS spectra with the CNFs/Si samples. The signals Si2p, C1s, N1s, and O1s are shown in the fitted spectra.

can be observed in Fig. 3. Moreover, the $\mathrm{CNF} / \mathrm{Si} 0$ sample shows two broad peaks around $25^{\circ}$ and $43^{\circ}$, which are attributed to the amorphous state and the (002) (100) reflection planes of the carbon structure.

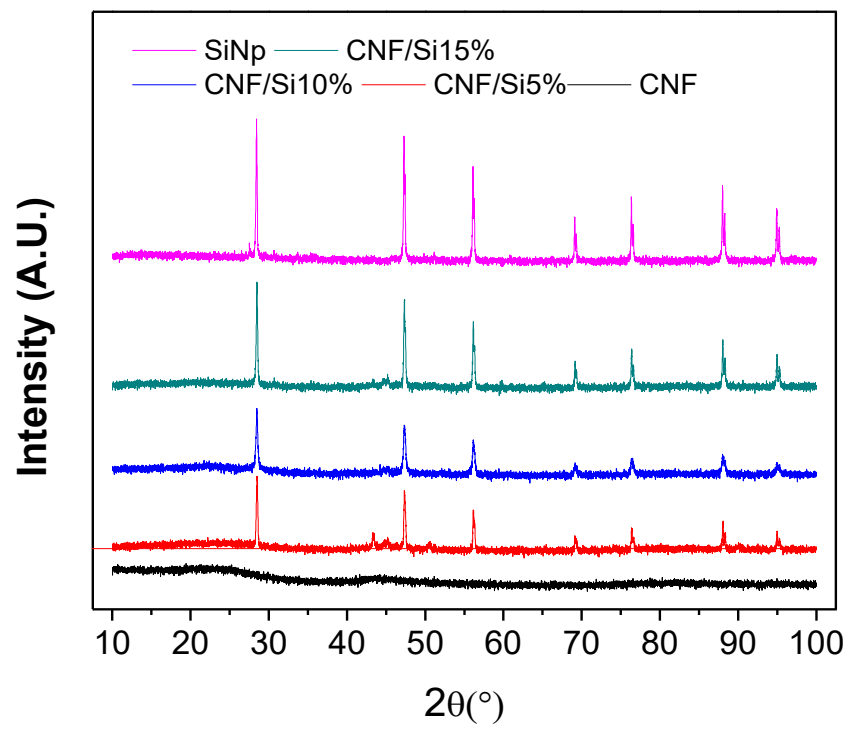

Fig. 4 XRD spectra of all CNFs samples.

The electrochemical performance of CNF, and the effect of $\mathrm{Si}$ addition on specific capacity, redox behavior, stability, and rate performance, were analyzed in Fig. 5. Firstly, cyclic voltammetry (CV) (Fig. S2) and differential capacity plots (DCPs) (Fig. S3) of CNF found that CNF displays a broad electrochemical activity over the entire $0.01-3.0 \mathrm{~V} v s \mathrm{Li} / \mathrm{Li}^{+}$ potential window. However, most of the capacity is achieved within a narrower $0.01-1.0 \mathrm{~V} v s \mathrm{Li} / \mathrm{Li}^{+}$window. Consequently, all cells were cycled between $0.01-1.0 \mathrm{~V} v s \mathrm{Li} / \mathrm{Li}^{+}$. From the DCPs, CNF shows no distinct redox peaks, with a sharp peak in the anodic scan attenuating over successive cycles (Fig. 5a). The redox behavior of CNF/Si_ 5 (red), CNF/Si_10 (blue), and $\mathrm{CNF} / \mathrm{Si} \_15$ (green) is predominated by a two-step lithaitiondelithiation mechanism, characteristic of Si. In the cathodic scan, lithiation is governed by two broad peaks at 0.23 and $0.09 \mathrm{~V}$, corresponding to $\mathrm{Si} \rightarrow \mathrm{Li}_{x} \mathrm{Si}$ and $\mathrm{Li}_{\mathrm{x}} \mathrm{Si} \rightarrow \mathrm{Li}_{15} \mathrm{Si}_{4}$ phase transitions, respectively. In the anodic scan, broad peaks at 0.29 and $0.46 \mathrm{~V}$ represent $\mathrm{Si}$ delithiation, first forming the intermediate $\mathrm{Li}_{\mathrm{x}} \mathrm{Si}$, and then forming $\mathrm{Si}$. Extended $\mathrm{CVs}$ and DCPs of $\mathrm{CNF} / \mathrm{Si}$ are provided in Fig. S4 and Fig. S5, respectively. Notably, the sharp peak at $0.44 \mathrm{~V}$ in the anodic scan corresponds to crystalline $\mathrm{Si}$ (c-Si). Electrochemical cycling induces the amorphization of $\mathrm{c}-\mathrm{Si}$, as evidenced by the attenuation of this sharp peak in favor of two broader delithiation peaks (Fig. S4). GCD profiles reflect this behavior, with $\mathrm{Si}$ addition forming two distinct sets of charge and discharge plateaus, illustrating the two-step redox behavior of $\mathrm{Si}$ (Fig. 5b). The addition of Si elevated the achievable specific capacity of CNF, with CNF, CNF/Si_5, 

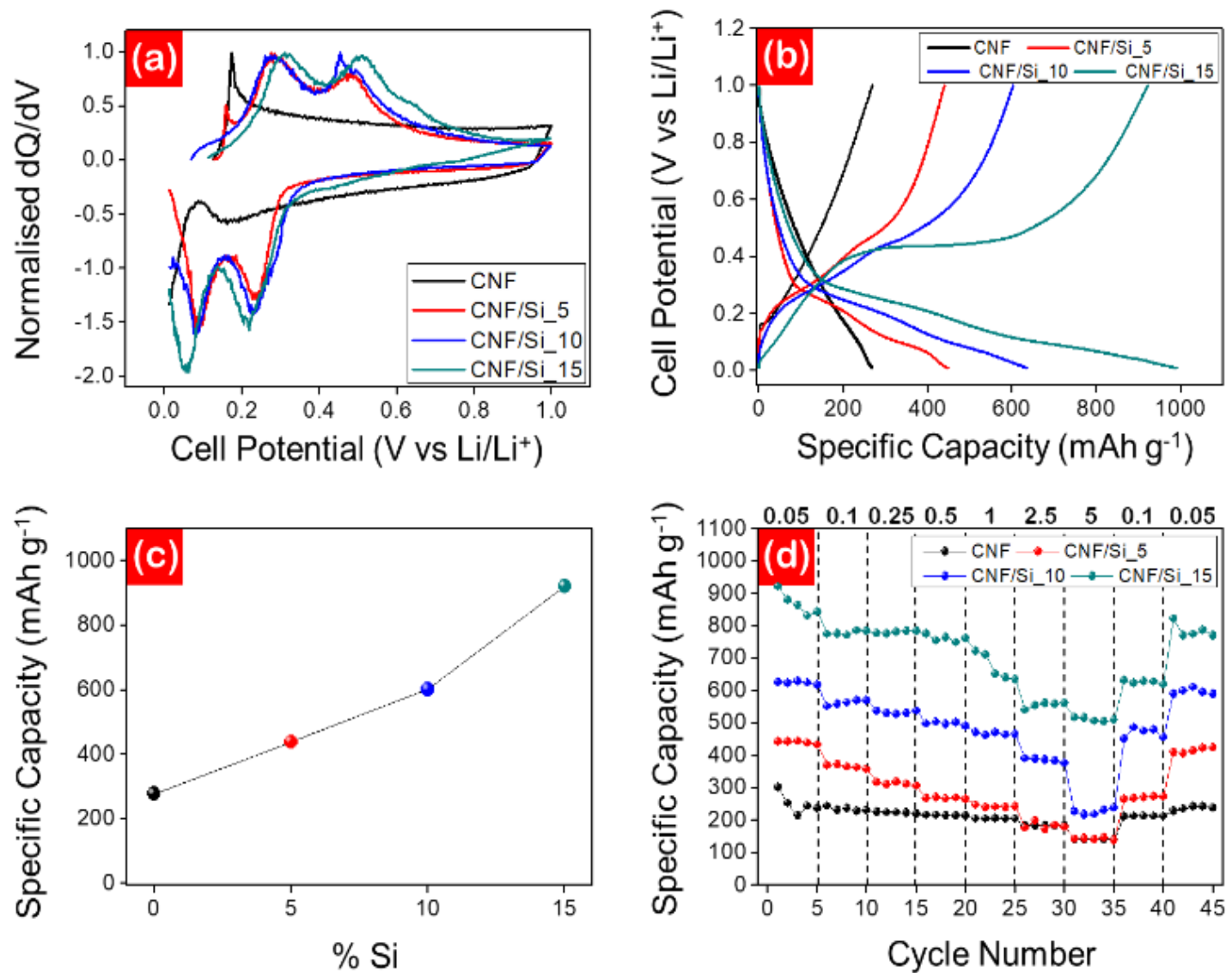

Fig. 5 Electrochemical analysis of $\mathrm{CNF}$ and $\mathrm{CNF} / \mathrm{Si}$ as a function of Si content. (a) Normalized differential capacity plots (DCPs) and (b) galvanostatic charge-discharge (GCD) profiles. (c) Relationship between specific capacity and Si content (10 ${ }^{\text {th }}$ cycle) and (d) rate capability testing (RCT) of CNF (black), CNF/Si_5 (red), CNF/Si_10 (blue) and CNF/Si_15 (green). Cells were cycled between 0.01-1.0 V vs $\mathrm{Li} / \mathrm{Li}^{+}$. RCT current density values are given in $\mathrm{A} \mathrm{g}^{-1}$.

$\mathrm{CNF} / \mathrm{Si} 10$ and $\mathrm{CNF} / \mathrm{Si} 15$ reached respective capacity values of 274, 439, 602, and $921 \mathrm{mAh} \mathrm{g}^{-1}$ (Fig. 5c). CNF demonstrated excellent rate performance, reaching $142 \mathrm{mAh}$ $\mathrm{g}$ at $5 \mathrm{~A} \mathrm{~g}^{-1}$ (56\% of $0.05 \mathrm{~A} \mathrm{~g}^{-1}$ capacity), and recovering $97.1 \%$ capacity after rate testing. $\mathrm{CNF} / \mathrm{Si} 5, \mathrm{CNF} / \mathrm{Si} 10$, and $\mathrm{CNF} / \mathrm{Si} 15$ retain favorable capacities after rate testing, recovering 96.9\%, 96.4\%, and 91.2\%. Low-level $\mathrm{Si}$ addition did not improve fast-rate performance, with $\mathrm{CNF} / \mathrm{Si} 5$ and $\mathrm{CNF} / \mathrm{Si} 10$ reaching $32.3 \%$ and $38.8 \%$ of their $0.05 \mathrm{~A} \mathrm{~g}^{-1}$ capacity, when discharged at $5 \mathrm{~A} \mathrm{~g}^{-1}$. Notably, CNF/Si_15 reached $62.3 \%$ of its $0.05 \mathrm{~A} \mathrm{~g}^{-1}$ capacity when discharged at 5 $\mathrm{A} \mathrm{g}^{-1}$, higher than the bare CNF anode.

The long-term stability of these composite anodes was tested and compared to the CNF baseline (Fig. 6). CNF demonstrates excellent stability, reaching 96.2\% retention after 200 cycles with an average coulombic efficiency (CE) of 99.1\%. Comparably, CNF/Si_5 (Fig. 6b), CNF/Si_10 (Fig. 6c), and CNF/Si_15 (Fig. 6d) reach capacity retentions of $94.9 \%$, $90.1 \%$, and $75.4 \%$ after 200 cycles, with average coulombic efficiencies (CEs) of 98.9\%, 98.6\%, and 98.5\%. Corresponding DCPs are provided in Fig. S5. Overall, Si addition elevates an achievable capacity with no significant reduction in average CE. Notably, a low-level addition of Si to
CNF improved initial CE over the bare CNF, with CNF and $\mathrm{CNF} / \mathrm{Si} 5$ delivering initial $\mathrm{CEs}$ of $51.0 \%$ and $70.5 \%$, respectively. Further addition of $\mathrm{Si}$ in $\mathrm{CNF} / \mathrm{Si} 10$ and $\mathrm{CNF} / \mathrm{Si} 15$ did lower initial CE, returning respective values of $62.7 \%$ and $59.5 \%$. Increased capacity does come at the cost of a slightly accelerated capacity fade rate. $\mathrm{CNF} / \mathrm{Si} 5$ and $\mathrm{CNF} / \mathrm{Si} 10$ demonstrate favorable stability, however, the increased $\mathrm{Si}$ content of CNF/Si_15 impacts capacity retention. Low-level additions of $\mathrm{Si}$ (i.e., 5-10 wt\%) to CNF proved optimal for enhancing specific capacity, while concurrently showing favorable long-term stability. Post-mortem analysis of the composite anodes shows no notable differences in postcycled morphology, with all composite formulations remaining well-adhered to the $\mathrm{Cu}$ foil after 200 cycles (Fig. S7).

The capacity values obtained in the present study are slightly lower compared to the petroleum-based CNFs with $\mathrm{Si}$ NPs, which are typically in the range of 1300-1900 $\mathrm{mAh} \mathrm{g}^{-1}$. [31,32] However, the Si load of the petroleum-based CNFs is higher than $15 \%$ due to the fact that the precursor solutions are easier to process compared to the lignin/PLA solutions, admitting more Si NPs loads $\left(>25 \%{ }^{[31]}\right)$. Comparing to other types of sustainable carbon such as: activated carbon- 

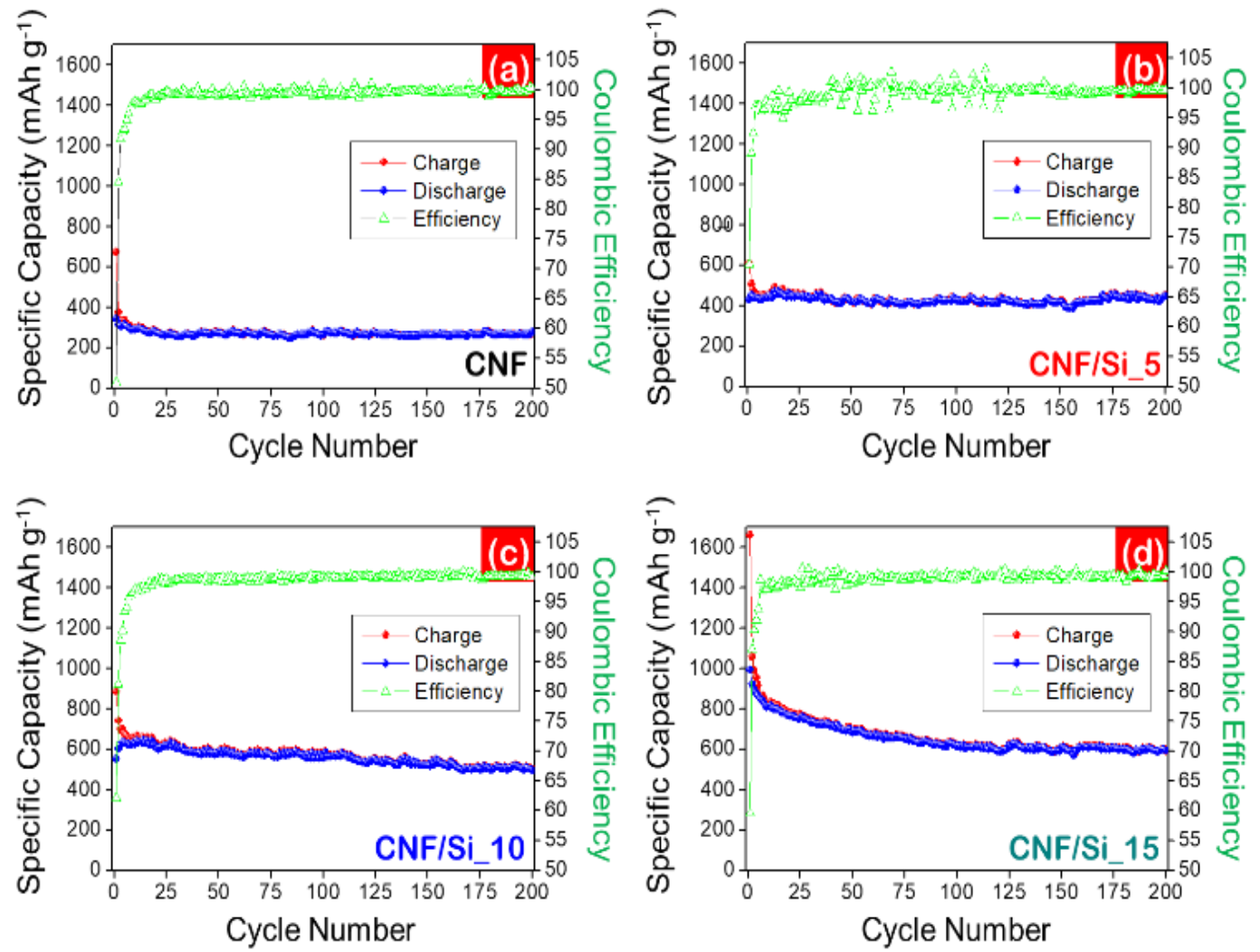

Fig. 6 Long-term charge-discharge behavior and corresponding CEs of (a) CNF, (b) CNF/Si_5, (c) CNF/Si_10, and (d) CNF/Si_15. All cells were cycled between $0.01-1.0 \mathrm{~V} \mathrm{vs} \mathrm{Li/} / \mathrm{Li}^{+}$at $100 \mathrm{~mA} \mathrm{~g}^{-1}$.

decorated spherical silicon composites derived from risk husk $\left(716 \mathrm{mAh} \mathrm{g}^{-1}\right)^{[33]}$ and spherical activated-carbon nanoparticles derived from green tea $\left.\left(781 \mathrm{mAh} \mathrm{g}^{-1}\right)\right)^{[34]}$ the results of $\mathrm{CNFs} / \mathrm{Si}$ derived from lignin/PLA blends showed better capacity values.

\section{Conclusions}

Precursor blends of lignin with PLA with the addition of Si at 5,10 , and $15 \%$ were successfully prepared by electrospinning, stabilized, and subsequently converted to carbon nanofibers. The addition of PLA provides a porous morphology due to its volatile nature during carbonization. Si nanoparticles were distributed homogeneously in the fibers grouped in small clusters. Very high capacity values were obtained for nanofibers produced from precursors containing $15 \%$ of $\mathrm{Si}$ reaching $921 \mathrm{mAh} \mathrm{g}^{-1}$. These results provide a clear path for lignin valorization in the next generation of LIBs lowering cost and improving performance along with increased sustainability associated with the LIBs manufacturing process.

\section{Acknowledgments}

$\mathrm{MC}, \mathrm{AB}$, and $\mathrm{MNC}$ acknowledge receiving funding from the BioBased Industries Joint Undertaking under the European Union's Horizon 2020 research and innovation program under grant agreement No 720707. G.A.C acknowledges the Irish Research Council and Intel Ireland under grant no. EPSPG/2017/233.

\section{Conflict of interest}

There are no conflicts to declare.

\section{Supporting information}

Applicable

\section{References}

[1] J. Fu, R. Liang, G. Liu, A. Yu, Z. Bai, L. Yang, Z. Chen, Advanced Materials, 2019, 31, 1805230, doi: 10.1002/adma.201805230.

[2] C. Wu, X. Tong, Y. Ai, D.-S. Liu, P. Yu, J. Wu, Z. M. Wang, Nano-Micro Letters, 2018, 10, 40, doi: 10.1007/s40820-0180194-4.

[3] B. Dunn, H. Kamath, J. M. Tarascon, Science, 2011, 334, 928935, doi: 10.1126/science.1212741.

[4] D. Lin, Y. Liu, Y. Cui, Nature Nanotechnology, 2017, 12, 194206, doi: 10.1038/nnano.2017.16.

[5] V. Ruiz, A. Pfrang, A. Kriston, N. Omar, P. Van den Bossche, L. Boon-Brett, Renewable and Sustainable Energy Reviews, 2018, 81, 1427-1452, doi: 10.1016/j.rser.2017.05.195.

[6] B. Nykvist, M. Nilsson, Nature Climate Change, 2015, 5, 329332, doi: 10.1038/nclimate2564.

[7] J. W. Choi, D. Aurbach, Nature Reviews Materials, 2016, 1,116, doi: 10.1038/natrevmats.2016.13.

[8] Q. Yang, Y. Geng, H. Dong, J. Zhang, X. Yu, L. Sun, X. Lu, Y. Chen, Journal of Cleaner Production, 2017, 161, 327-334, doi: 10.1016/j.jclepro.2017.05.131. 
[9] S. Wang, J. Yu, Waste Management \& Research, 2021, 39, 156-164, doi: 10.1177/0734242X20966637.

[10] M. Culebras, M. J. Sanchis, A. Beaucamp, M. Carsí, B. K. Kandola, A. R. Horrocks, G. Panzetti, C. Birkinshaw, M. N. Collins, Green Chemistry, 2018, 20, 4461-4472, doi: $10.1039 / \mathrm{c} 8 \mathrm{gc0} 01577 \mathrm{e}$

[11] M. Culebras, H. Geaney, A. Beaucamp, P. Upadhyaya, E. Dalton, K. M. Ryan, M. N. Collins, ChemSusChem, 2019, 12, 4516-4521, doi: 10.1002/cssc.201901562.

[12] S.-X. Wang, L. Yang, L. P. Stubbs, X. Li, C. He, ACS Applied Materials \& Interfaces, 2013, 5, 12275-12282, doi: 10.1021/am4043867.

[13] W. E. Tenhaeff, O. Rios, K. More, M. A. McGuire, Advanced Functional Materials, 2014, 24, 86-94, doi: 10.1002/adfm.201301420.

[14] B. Zhang, Y. Yu, Z.-L. Xu, S. Abouali, M. Akbari, Y.-B. He, F. Kang, J.-K. Kim, Advanced Energy Materials, 2014, 4, 1301448, doi: 10.1002/aenm.201301448.

[15] A. P. Nowak, J. Hagberg, S. Leijonmarck, H. Schweinebarth, D. Baker, A. Uhlin, P. Tomani, G. Lindbergh, Holzforschung, 2018, 72, 81-90, doi: 10.1515/hf-2017-0044.

[16] S.-X. Wang, L. Yang, L. P. Stubbs, X. Li, C. He, ACS Applied Materials \& Interfaces, 2013, 5, 12275-12282, doi: 10.1021/am4043867.

[17] J. Jin, B.-J. Yu, Z.-Q. Shi, C.-Y. Wang, C.-B. Chong, Journal of Power Sources, 2014, 272, 800-807, doi: 10.1016/j.jpowsour.2014.08.119.

[18] D. Nan, Z. H. Huang, R. Lv, L. Yang, J. G. Wang, W. Shen, Y. Lin, X. Yu, L. Ye, H. Sun, F. Kang, Journal of Materials Chemistry A, 2014, 2, 19678-19684, doi: 10.1039/c4ta03868a.

[19] Q. Yang, T. Sun, J. Y. Yu, J. X. Ma, Chinese Chemical Letters, 2016, 27, 412-416, doi: 10.1016/j.cclet.2015.12.025.

[20] X. Shen, D. Mu, S. Chen, R. Huang, F. Wu, Journal of Materials Chemistry A, 2014, 2, 4309, doi: 10.1039/c3ta14685e. [21] K. B. Kim, N. A. Dunlap, S. S. Han, J. J. Jeong, S. C. Kim, K. H. Oh, S. H. Lee, Journal of The Electrochemical Society, 2018, 165, A1903-A1908, doi: 10.1149/2.1491809jes.

[22] S. W. Hwang, D. H. Park, D. H. Kang, S. B. Lee, J. K. Shim, Journal of Applied Polymer Science, 2016, 133, 43388, doi: 10.1002/app.43388.

[23] L. Qie, W. M. Chen, Z. H. Wang, Q. G. Shao, X. Li, L. X. Yuan, X. L. Hu, W. X. Zhang, Y. H. Huang, Advanced Materials, 2012, 24, 2047-2050, doi: 10.1002/adma.201104634.

[24] C. Kim, K. S. Yang, M. Kojima, K. Yoshida, Y. J. Kim, Y. A. Kim, M. Endo, Advanced Functional Materials, 2006, 16, 2393 2397, doi: 10.1002/adfm.200500911.

[25] Y. Chen, X. Li, K. Park, J. Song, J. Hong, L. Zhou, Y.-W. Mai, H. Huang, J. B. Goodenough, Journal of the American Chemical Society, 2013, 135, 16280-16283, doi: 10.1021/ja408421n.

[26] L. Ji, X. Zhang, Nanotechnology, 2009, 20, 155705, doi: 10.1088/0957-4484/20/15/155705.

[27] A. Beaucamp, M. Culebras, M. N. Collins, Green Chemistry, 2021, 23, 5696-5705, doi: 10.1039/d1gc02062e.

[28] D. S. Knight, W. B. White, Journal of Materials Research,
1989, 4, 385-393, doi: 10.1557/jmr.1989.0385.

[29] A. C. Ferrari, J. Robertson, Physical Review B, 2001, 64, 075414, doi: 10.1103/physrevb.64.075414.

[30] S. Periasamy, S. Venkidusamy, R. Venkatesan, J. Mayandi, J. Pearce, J. H. Selj, R. Veerabahu, Zeitschrift Für Physikalische Chemie, 2017, 231, 1585-1598, doi: 10.1515/zpch-2016-0961.

[31] S. J. Kim, M. C. Kim, S. B. Han, G. H. Lee, H. S. Choe, S. H. Moon, D. H. Kwak, S. Hong, K. W. Park, Journal of Industrial and Engineering Chemistry, 2017, 49, 105-111, doi: 10.1016/j.jiec.2017.01.014.

[32] E. S. Park, H. K. Park, H. S. Park, C. S. Lee, Journal of Nanoscience and Nanotechnology, 2015, 15, 8961-8970, doi: 10.1166/jnn.2015.11554.

[33] S. Sekar, A. T. Aqueel Ahmed, A. I. Inamdar, Y. Lee, H. Im, D. Y. Kim, S. Lee, Nanomaterials, 2019, 9, 1055, doi: 10.3390/nano9071055.

[34] S. Sankar, S. Saravanan, A. T. A. Ahmed, A. I. Inamdar, H. Im, S. Lee, D. Y. Kim, Materials Letters, 2019, 240, 189-192, doi: 10.1016/j.matlet.2018.12.143.

\section{Author information}

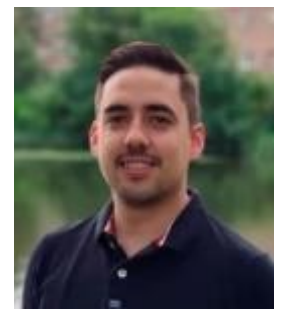

Mario Culebras, PhD in Chemistry obtained at the University of Valencia (2017). Mario Culebras currently works as assistant professor in the physical chemistry department at the University of Valencia. He is also part of the Institute of Material Science at the University of Valencia where he is doing research focused on the recovery of biomass residues to produce advanced nanomaterials, publishing 56 articles in peer-reviewed journals, 8 patents, 2 book chapters and presenting more than 42 papers at renowned international conferences. In addition, he works on several national and international research projects, being the principal investigator of several of them.

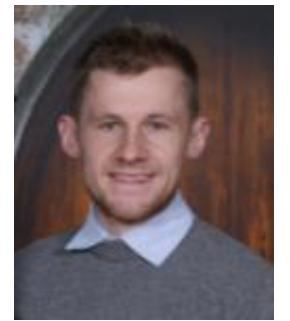

Gearoid Collins received his undergraduate degree in Nanoscience from Trinity College, Dublin in 2017. He was awarded his PhD in Materials Science by the University of Limerick in 2022, in partnership with the Irish Research Council and Intel Ireland. His PhD research has focused on developing new approaches to fabricate nanostructured anode materials for energy-dense lithium-ion batteries; including developing highly conductive nanowire (NW)-based anodes for low-temperature applications; improving material loadings of directly grown $\mathrm{Si}$ NWs using nanotextured $3 D$ growth templates; scalable synthesis of Si NW/graphite composites; and investigating the utility of nanostructured TMD conversion materials as suitable battery anodes. He currently works as a Process Engineer for Intel Ireland. 


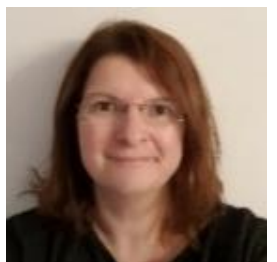

Anne Beaucamp obtained a PhD on material science in the University of Limerick (Ireland) in 2021. She has extended experience on the development of sustainable carbon materials from lignocellulosic feed stocks. She currently works as a Post Doctorate fellow in the University of Limerick, where she is developing her expertise on biopolymer chemistry, materials processing, biomaterial modifications and the development of nanostructured carbon materials from lignin sustainable resources. So far, she has authored 5 articles in the field of lignin valorisation and her work has been cited over 580 times with an h-index of 6. She is also the co-author of a patent on lignin valorisation for biomedical application.

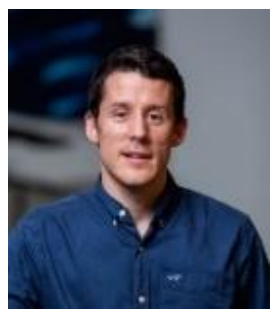

Hugh Geaney finished a degree in Industrial Chemistry in 2008 and a PhD in Chemistry in 2012 (both from UL). He subsequently moved to UCC as a postdoctoral researcher on the EU FP7 project STABLE, working on $\mathrm{Li}-\mathrm{O} 2$ batteries. Following that, he was a senior postdoctoral researcher in UCC, investigating porous materials for Li-ion battery applications. In 2016 he returned to UL as a postdoctoral researcher on an Enterprise Ireland commercialization project. In 2019, he received a SIRG (starting investigator research grant) and became an independent, Principal Investigator. Since 2020, Hugh has been a lecturer in Chemistry in the Department of Chemical Science in the University of Limerick

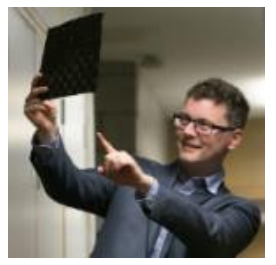

Dr Maurice N. Collins is a senior lecturer in the School of Engineering at the University of Limerick. He is Principal Investigator (PI) at the Bernal Institute, the Health Research Institute and FI at the SFI AMBER centre based in Trinity College Dublin. He coordinated the H2020 funded LIBRE consortium (lignin for carbon fiber), the largest consortium in biobased carbon fibre research in Europe as well as being PI on multiple national funded projects. He is co-PI of the H2020 funded VIBES consortium. His expertise includes regenerative medicine, hydrogels and biobased carbon precursor materials as well as the development of $3 D$ printable Polymers. Dr Collins has a strong track record in attracting industrially funded research projects. His industrial work has led to 4 licensing agreements with 8 patents filed. Coupled to this, he has authored $>150$ publications on Materials Science related topics and his research has featured in various national and international media outlets. His research has been recognised through various awards and he is Course Director for the MSc in Biomedical Device Materials. He is editor of the international journal of biological macromolecules published by Elsevier and was recently awarded the Bernal Institute senior researcher of the year. His current $h$-index is 40. He has been elected Fellow of the Royal Society of Chemistry.

Publisher's Note: Engineered Science Publisher remains neutral with regard to jurisdictional claims in published maps and institutional affiliations. 